\title{
Lightning fatalities and injuries in Turkey
}

\author{
Ş. Tilev-Tanriover ${ }^{1, a}$, A. Kahraman ${ }^{2}$, M. Kadioğlu ${ }^{1}$, and D. M. Schultz ${ }^{3}$ \\ ${ }^{1}$ Department of Meteorological Engineering, Istanbul Technical University, Istanbul, Turkey \\ ${ }^{2}$ Graduate School of Science, Engineering and Technology, Istanbul Technical University, Istanbul, Turkey \\ ${ }^{3}$ Centre for Atmospheric Science, School of Earth, Atmospheric and Environmental Sciences, University of Manchester, \\ Manchester, UK \\ ${ }^{a}$ now at: Centre for Atmospheric Science, School of Earth, Atmospheric and Environmental Sciences, University of \\ Manchester, Manchester, UK
}

Correspondence to: Ş. Tilev-Tanriover (tanriovers@itu.edu.tr)

Received: 25 November 2014 - Published in Nat. Hazards Earth Syst. Sci. Discuss.: 12 March 2015

Accepted: 14 July 2015 - Published: 20 August 2015

\begin{abstract}
A database of lightning-related fatalities and injuries in Turkey was constructed by collecting data from the Turkish State Meteorological Service, newspaper archives, European Severe Weather Database, and the internet. The database covers January 1930 to June 2014. In total, 742 lightning incidents causing human fatalities and injuries were found. Within these 742 incidents, there were 895 fatalities, 149 serious injuries, and 535 other injuries. Most of the incidents $(89 \%)$ occurred during April through September, with a peak in May and June (26 and $28 \%$ ) followed by July $(14 \%)$. Lightning-related fatalities and injuries were most frequent in the afternoon. Most of the incidents (86\%) occurred in rural areas, with only $14 \%$ in the urban areas. Approximately, two thirds of the victims with known gender were male. Because of the unrepresentativeness of the historical data, determining an average mortality rate over a long period is not possible. Nevertheless, there were 31 fatalities (0.42 per million) in 2012, 26 fatalities ( 0.35 per million) in 2013, and 25 fatalities ( 0.34 per million) in 2014 (as of June). There were 36 injuries ( 0.49 per million) in each of 2012 and 2013, and 62 injuries (0.84 per million) in 2014 (as of June).
\end{abstract}

\section{Introduction}

Lightning is responsible for an estimated 24000 fatalities and 240000 injuries every year globally (Holle and Lopez, 2003). In the USA (1959-2006) 101.2 people per year on average die due to lightning, a number that has decreased over time to about 45 per year by 2006 (Ashley and Gilson,
2009). In Canada, 9-10 lightning-related deaths and 92-164 injuries occur every year (Mills et al., 2008). In the UK there were 2 fatalities per year on average for the period of 1988 2012 (Elsom and Webb, 2014). Average fatality per year was 230 in Mexico for the period of 1979-2011 (Raga et al., 2014). Table 1 shows an average number of fatalities during a year per 1000000 population for some countries. Africa has the deadliest statistics. Although there are numerous difficulties that affect the compilation of such report-based data sets (e.g. data collection, population density distributions, socio-economic factors, telecommunication facilities), having these databases and related statistics is a necessity for each country for risk assessment.

As in other parts of the world, Turkey experiences a large number of deaths and injuries due to convective storms, particularly with lightning. Over a 23-year period (November 1975 to October 1998) at the Ankara Numune Teaching and Research Hospital, 22 patients were treated for lightning burns (Aslar et al., 2001). Also, case studies in Turkey have been published in medical journals on the effects of lightning strikes on the human body (e.g. Alyan et al., 2006; Celiköz et al., 1996; Aslan et al., 2004). Despite these studies, nationwide statistics on lightning deaths and injuries have not been compiled.

The purpose of this paper is to compile a database on lightning-strike incidences that have killed or injured people in Turkey. The data are gathered from various sources from January 1930 to June 2014. Although finding all incidents throughout history and creating a complete database is not possible, existing records can be used to determine how 
Table 1. Average fatality rates per million people per year for some countries.

\begin{tabular}{ll}
\hline Country & $\begin{array}{l}\text { Average fatality rate per million } \\
\text { people per year }\end{array}$ \\
\hline USA (1959-2006) & 0.44 (Ashley and Gilson, 2009) \\
Canada & 0.32 (Mills et al., 2008) \\
China (1997-2009) & 0.31 (Zhang et al., 2011) \\
UK (1993-1999) & 0.05 (Elsom, 2001) \\
Mexico (1979-2011) & 2.72 (Raga et al., 2014) \\
Malawi & 84 (Salerno et al., 2012) \\
Swaziland (2000-2007) & 15.5 (Dlamini, 2009) \\
\hline
\end{tabular}

frequent such lightning-strike incidences are, what their geographical distribution is, and what season or time of the day is most dangerous for people. Furthermore, some specific information (e.g. percentage of victims under trees) can help to create public awareness. Section 2 of this paper describes the data and the methods used. In particular, the sources of the records, how these sources were searched, and the characteristics of the records are described. Some observations on thunderstorms and lightning in Turkey are given in Sect. 3. In Sect. 4, statistics of the lightning incidents are presented. Section 5 summarizes the findings of this study.

\section{Data and methods}

Any lightning-strike event resulting in human injuries or fatalities is defined as an incident in this paper. Five sources were used to create a database of incidents: archives of the Turkish State Meteorological Service, electronic archives of two mainstream national newspapers (Cumhuriyet and Milliyet), European Severe Weather Database, and the internet (Fig. 1). These five data sources are presently described.

The first source was the Turkish State Meteorological Service climatological station data set, which routinely reports exceptional weather events, known as FEVK observations. FEVK is an abbreviation for the word fevkalade, which means exceptional, extraordinary in Turkish. These observations - which include the information on weatherrelated exceptional phenomena, human fatalities and injuries, and property damage - have been stored in the headquarters as hard copies since 1939. Scanned pdf and jpeg formatted records were obtained and manually searched, yielding 220 lightning incidents. Approximately one third of all incidents $(29.6 \%)$ were from this official source.

The second source was Cumhuriyet, a national newspaper with the biggest online archive in Turkey (Cumhuriyet archive, 2013). News from 1930 to the present week is accessible to registered users of the archive who purchase a membership. This archive was searched for the Turkish word ylldırım (cloud-to-ground lightning), yielding 333 in-

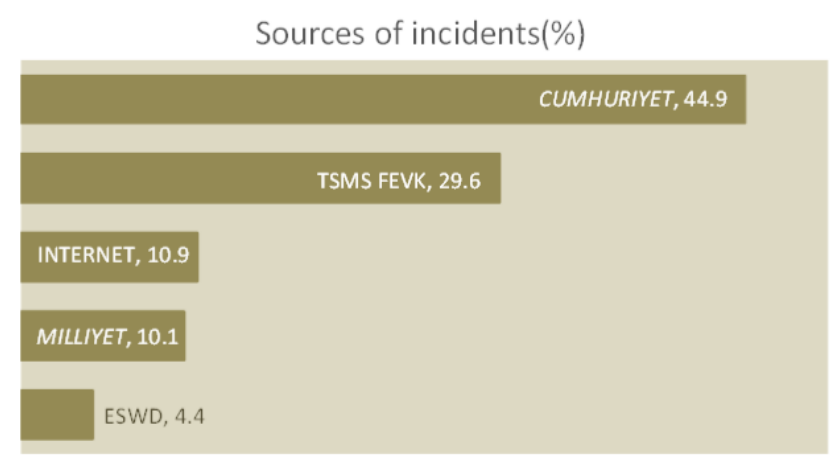

Figure 1. Relative contributions of lightning incident data sources to the total data set. TSMS is the Turkish State Meteorological Service, and ESWD is the European Severe Weather Database.

cidences. The biggest portion (44.9\%) of the incidents was from this archive, as it covered the longest time range.

The third source was the online archive of Milliyet, another national newspaper, which was also searched for lightning events using the same method (Milliyet archive, 2013). This archive includes news from 1950 to 2004 and is freely available to registered users. Seventy-five incidences $(10.1 \%)$ were from Milliyet. At the time of writing of this article, there are no other digital archives for old newspapers in Turkey.

A fourth source was the European Severe Weather Database (ESWD; http://www.essl.org/cgi-bin/eswd/eswd. cgi). The ESWD contributed 33 incidences (4.4\%), although damaging lightning phenomena was introduced as a separate category in ESWD only in 2011.

A fifth source was the Google.com.tr searches with the keyword ylldırm from 1 January 2012 to 30 June 2014. Eighty-one incidents (10.9\%) were found by internet searches. After including the internet searches and ESWD records, 42 incidents in each of 2012 and 2014 (as of June), and 34 incidents in 2013 were counted, which produced far more incidents than all other years in the previous decades.

Comparing all of these five sources led to only 17 duplicate reports. In case of a duplicate report, all available information from both sources was used. Then, the incident was assigned to the source containing the most informative report. After gathering all records and sifting out the duplicates, a database was built consisting of 742 incidences from 1930 to 2014 in Turkey. These known lightning incidents resulted in 895 fatalities, 149 serious injuries, and 536 other injuries. Injuries mentioned as serious in the reports were classified as serious injury in the database.

One weakness of the newspaper-based records was that the exact date of some incidents may not be known as the occurrence may be listed as "last week" or "the previous day". When there is no precise information about the exact date of the event, but the month is known, the month is used in relevant figures and classifications, but unreliable situations are not included in these statistics. Towns or vil- 


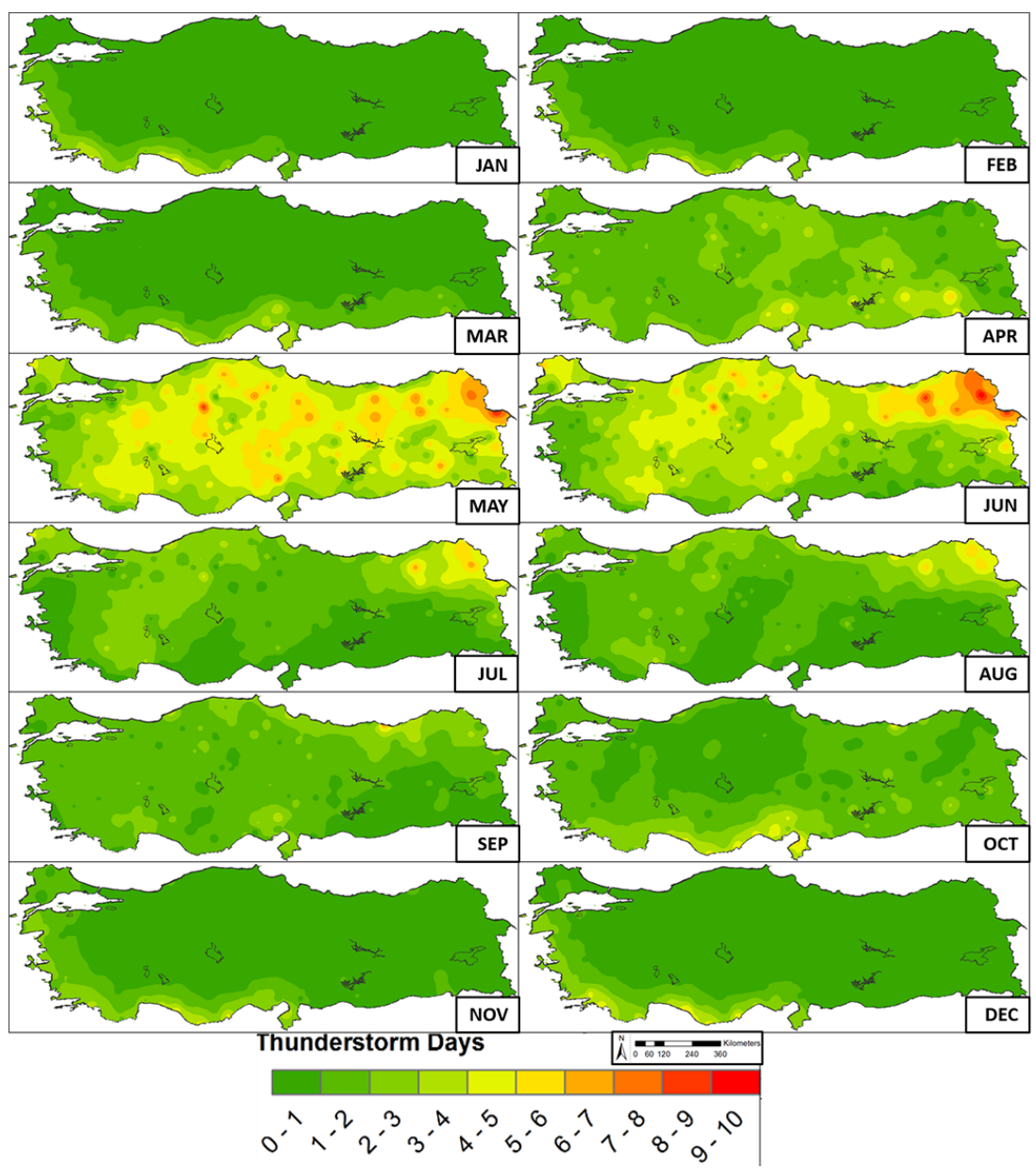

Figure 2. Average number of thunderstorm days in Turkey for each month. Data were provided by the Turkish State Meteorological Service.

lages that changed their name were another important problem with old records. Further investigations were done to find the correct geographical locations of the old records that took place in a renamed town or village (e.g. Issizviran Village is now called Issızören Village, Şeytanbudaklar Village is now called Uluçam Village, Rizok Village is now called Oymak Village).

\section{Thunderstorms and lightning in Turkey}

Station observations of the Turkish State Meteorological Service indicate that thunderstorms occur in Turkey throughout the year. Monthly-average numbers of thunderstorm days at 277 Turkish State Meteorological Service stations between 1960-2013 were bilinearly interpolated with an inverse distance weighting method (variable radius, 2 nd power) on a grid of $263 \times 100$ points to produce a gridded analysis of thunderstorm frequency (Fig. 2). Thunderstorms were most frequent in May and June all around Turkey, especially over the inland and northeastern parts. The maximum thunderstorm frequency shifts to the Aegean and Mediterranean coasts from late autumn to early spring, while the rest of Turkey has relatively infrequent thunderstorms.

Geographical distribution map (Fig. 3) shows that average stroke density is lowest in southern parts of the central Turkey and is highest along the coasts with maxima around Mugla, Hatay, and Adana (see Fig. 8 for locations). GLD360 (Global Lightning Data set 360) lightning observation data provided by Vaisala over a 2-year period (1 October 2011 to 30 September 2013) are used to display annual (Fig. 4a) and diurnal (Fig. 4b) distributions of lightning over Turkey (For technical information about the data see Said et al., 2010, 2013). The annual distribution of lightning was consistent with the annual distribution of thunderstorm observations as expected (cf. Figs. 2 and 4a). Both lightning and thunderstorms were most frequent in May and June. Figure $4 \mathrm{~b}$ shows that most of the lightning strikes occurred in the afternoon.

\section{Results}

Because the data set is not homogeneous throughout the period, it is not possible to talk about the incident trends 


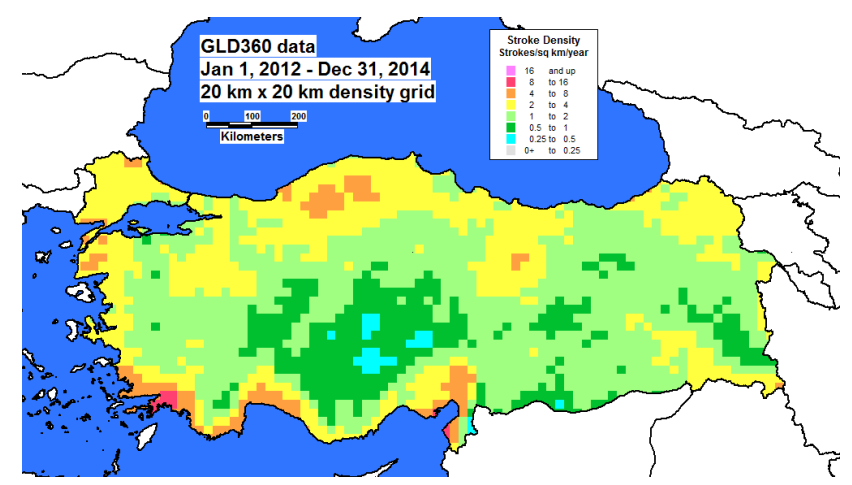

Figure 3. Geographical distribution of lightning over Turkey between 1 January 2012 and 31 December 2014 in strokes $\mathrm{km}^{-2}$ year $^{-1}$ (provided by Vaisala).

with confidence. However, an increasing number of lightning causalities and injuries in the 1950s and 1960s, and a decrease in late 1980s and 1990s, are notable (Fig. 5). According to the Turkish Statistical Institute, the population of Turkey increased rapidly from 1939 to 2012, from 20 million to over 75 million (see ahead to Fig. 12) (http: //www.turkstat.gov.tr/Start.do). Due to the unrepresentativeness of the historical data and missing records, determining the average mortality rate for a long period was not possible. With the inclusion of incidents from the ESWD and the internet, the number of incidents are quite high for the last 3 years. The total number of fatalities was 31 persons in 2012 ( 0.42 per million), 26 persons ( 0.35 per million) in 2013, and 25 persons ( 0.34 per million) in 2014 (January-June). The total number of injuries was 36 persons ( 0.49 per million) in each of 2012 and 2013, and 62 persons ( 0.84 per million) in 2014 (January-June).

Monthly and diurnal distributions of the incidents and some other aspects of the incidents (e.g. the places of occurrence, the genders of victims) are analysed. Most of the incidents $(89 \%)$ occurred from April through September with a peak in May and June (26 and $28 \%$ ), followed by July (14\%) (Fig. 6). Sixty-seven percent of all incidents occurred in these 3 months. Incidents peaked in late spring, similar to the peaks in thunderstorm and lightning observations (Figs. 2 and $4 \mathrm{a}$ ). This peak was also consistent with the Turkish severe storm climate, as the large hail and continental tornado frequencies increase in Turkey around May (Kahraman and Markowski, 2014; Kahraman et al., 2014). Another reason for this peak is the increasing number of human activities that move outside in the spring, particularly during agriculture and shepherding.

There were local or UTC time information in 136 of the reports. Local times were converted into UTC; local time is UTC+2 in Turkey from October to March and UTC+3 from April to September due to daylight savings. More than half of all incidents (54\%) occur between 09:00-15:00 UTC (Fig. 7), which is as expected considering the increasing
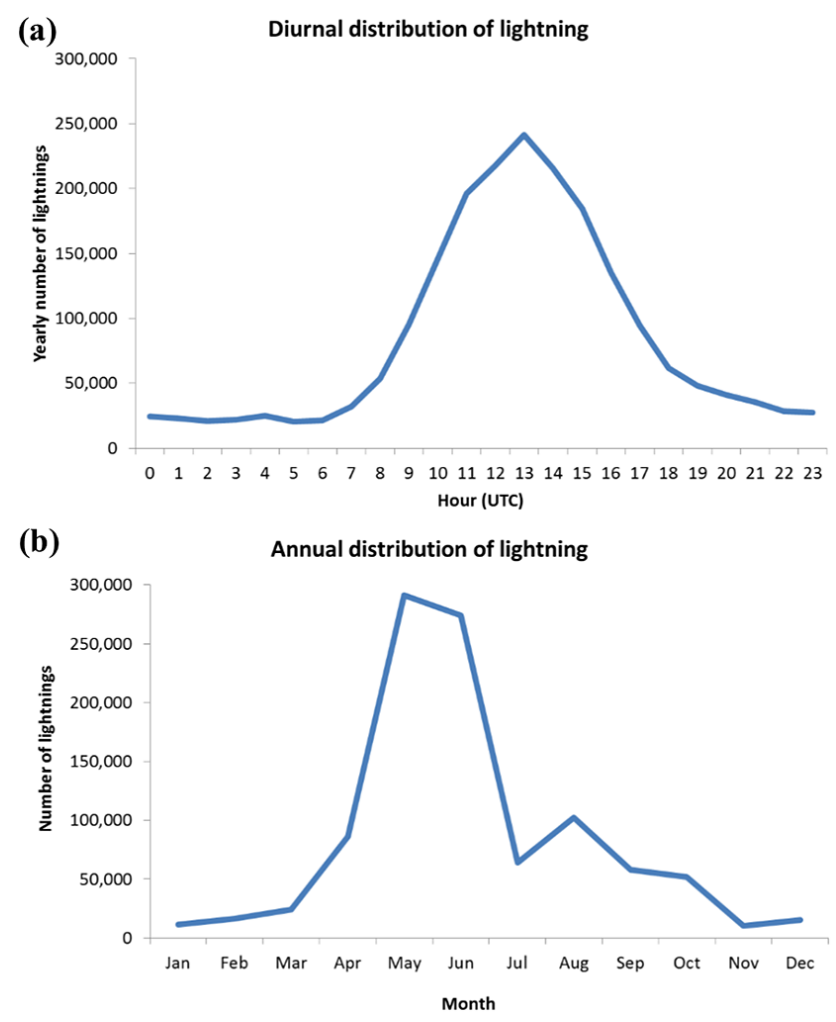

Figure 4. (a) Annual and (b) diurnal distribution of lightning over Turkey between 1 October 2011 and 30 September 2013. Local time in Turkey is UTC +2 from October to March and UTC +3 from April to September due to daylight saving time. Data were provided by Vaisala.

number of lightning at this time of the day (Fig. 4a). Some other severe storm-related phenomena (i.e. severe hail and tornadoes) are also most frequent in the afternoon in Turkey (Kahraman and Markowski, 2014; Kahraman et al., 2014). Incidents are rare during the night.

There are more incidents near highly populated areas, namely western Turkey and especially Istanbul (Fig. 8). There is also a lower density of incidents over central Turkey. The lowest density of lightning over central Turkey and relatively low density over eastern Turkey were similar to the geographical distribution of lightning-related incidents (cf. Figs. 3 and 8). The number of incidents in Istanbul is higher compared to the other regions with the same stroke density, because of the massive population of the city (number of the incidents occurred in Istanbul is 40 which is $5.4 \%$ of all incidents, whereas stroke density over the city is about $0.5-$ $2 \mathrm{~km}^{-2}$ year $^{-1}$ ).

The geographical distribution of lightning incidents for each month (Fig. 9) suggests that the relatively rare occurrences in winter months almost always happened along the southern and western coasts, which follows the thunderstorm climate (Fig. 2). The number of incidents increased in southeastern Turkey in April. By May and June, incidents occurred 
Lightning incidents, fatalities and injuries 1930-2014

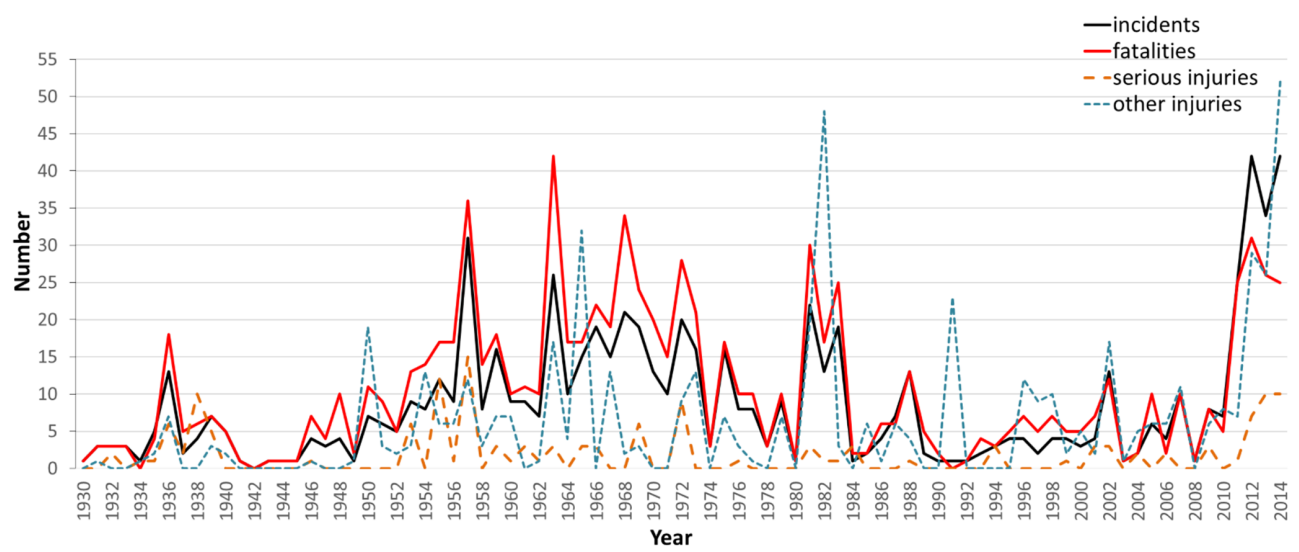

Figure 5. Number of lightning incidents, fatalities and injuries (serious and other) per year (January 1930 to June 2014).

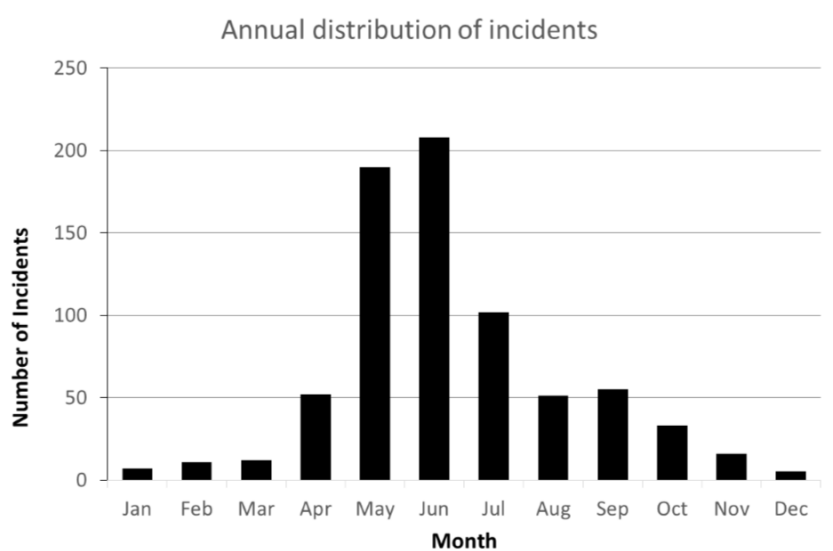

Figure 6. Annual distribution of the total number of lightning incidents by month (January 1930 to June 2014).

in all parts of Turkey. By July, the number of incidents in the east began to decline, and, after August and September, the number of incidents sharply decreased across most of Turkey.

Of the 1580 people in our database who were killed or injured, the gender of $849(53.7 \%)$ was known. For 578 fatalities, $386(67 \%)$ were male and $192(33 \%)$ were female (Fig. 10). These values are more balanced than for other countries. For example, comparing the gender of lightning fatalities in the US from two data sets 100 years apart shows that the percentage of events resulting in only male fatalities was over $70 \%$ in the 1890 s, but rose to $80 \%$ in the 1990 s (Holle et al., 2005). In Canada, $84 \%$ of all lightning fatalities (1921-2003, excluding 1950-1964) were male (Mills et al., 2008). The percentage of male fatalities is also large in Mexico: $79 \%$ (Raga et al., 2014). In contrast, the Turkish data were more comparable to that in the United Kingdom (19931999) where $72.7 \%$ of deaths were male (Elsom, 2001).

The percentage of men and women with serious or other injuries is not that different from that of the fatalities

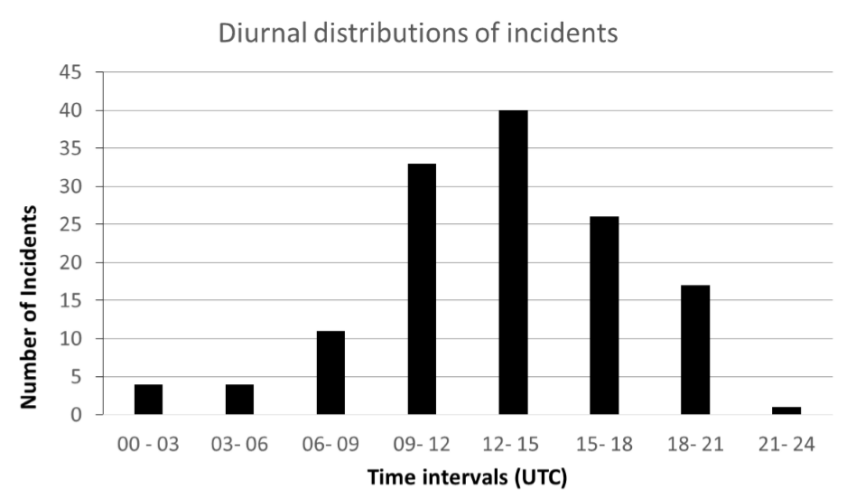

Figure 7. Diurnal distribution of the total number of lightning incidents by $3 \mathrm{~h}$ period (January 1930 to June 2014). Local time in Turkey is UTC+2 from October to March and UTC+3 from April to September due to daylight saving time.

(Fig. 10). Combining all three categories in Fig. 10, 553 of 849 people struck by lightning were men $(65 \%)$ in Turkey, just like the $65 \%$ in the UK (Elsom, 2001). The reason why men are twice as likely to be struck than women is that men are more likely to be doing outdoor jobs. However, the female fraction is higher compared to the statistics from the other countries, which is presumably because more women work in agriculture in Turkey than the others. The percentage of female employment in agriculture is $37 \%$ in Turkey (2012), whereas it is $1 \%$ in US (2010), $1 \%$ in Canada (2008), $4 \%$ in Mexico (2011) and $1 \%$ in UK (2012) (Data retrieved from The World Bank website: http://data.worldbank.org/indicator/SL.AGR.EMPL.FE. ZS/countries/1W-CA-GB-US-MX-TR?display=map).

Age information was available for a small number of events. Out of a total number of 369 incidents where ages were known, ages of 258 (29\%) deaths, 47 (32\%) seriously injured and $64(12 \%)$ injured victims were known. Most of the victims were young people; $59 \%$ of deaths were younger 


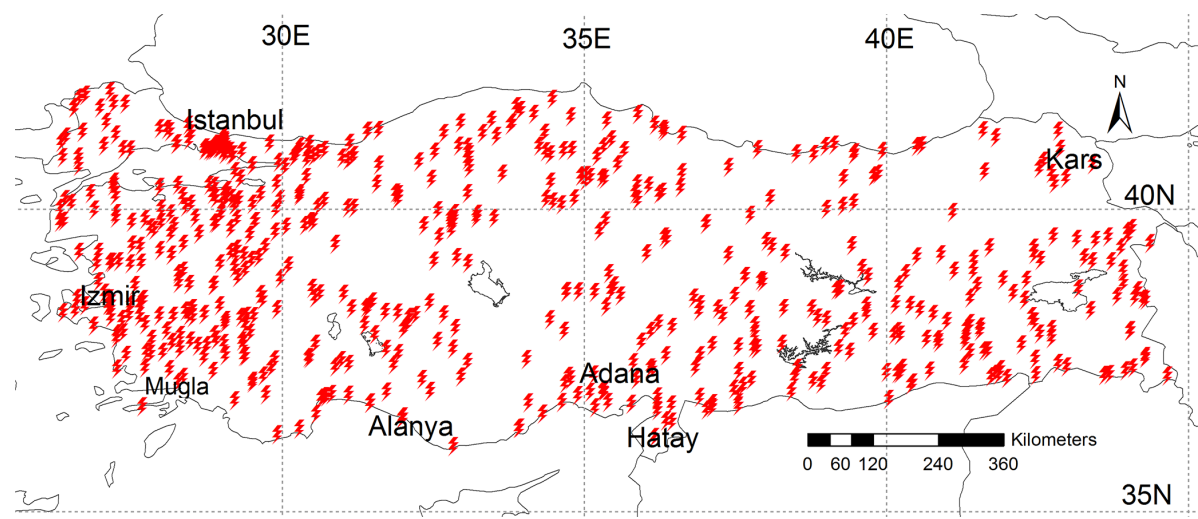

Figure 8. Locations of lightning incidents resulting in fatalities, injuries, or both, in Turkey (January 1930 to June 2014). Multiple fatalities and injuries may occur at each red point.

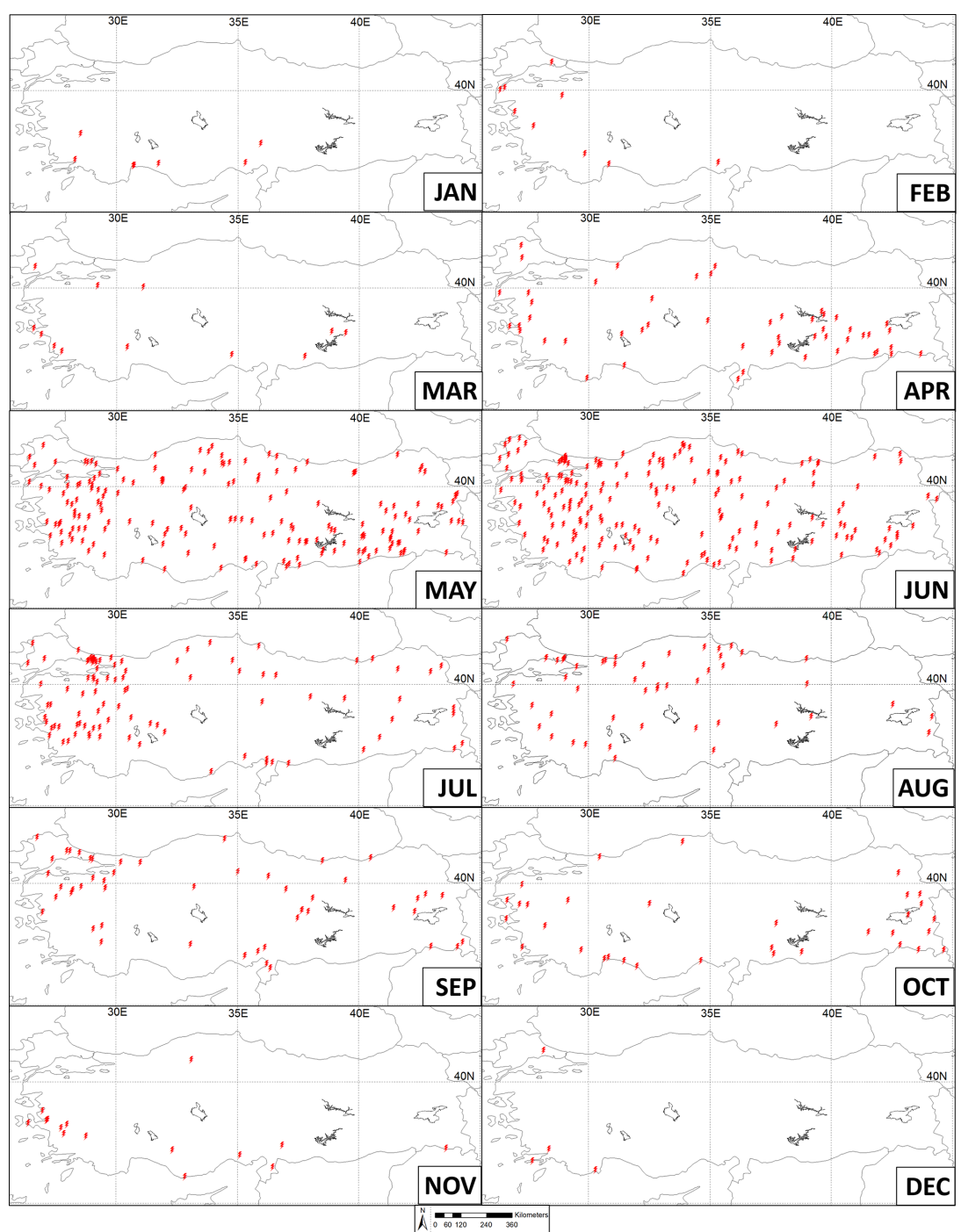

Figure 9. Locations of lightning incidents resulting in fatalities, injuries, or both, by month (January 1930 to June 2014). Multiple fatalities and injuries may occur at each red point. 


\section{Gender distribution of victims}

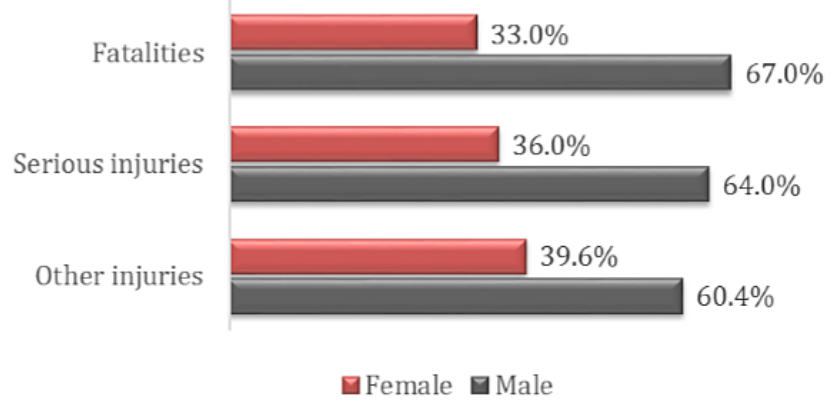

Figure 10. Gender distribution of lightning victims by fatalities, serious injuries, and other injuries (January 1930 to June 2014).

\section{Age distribution of victims}

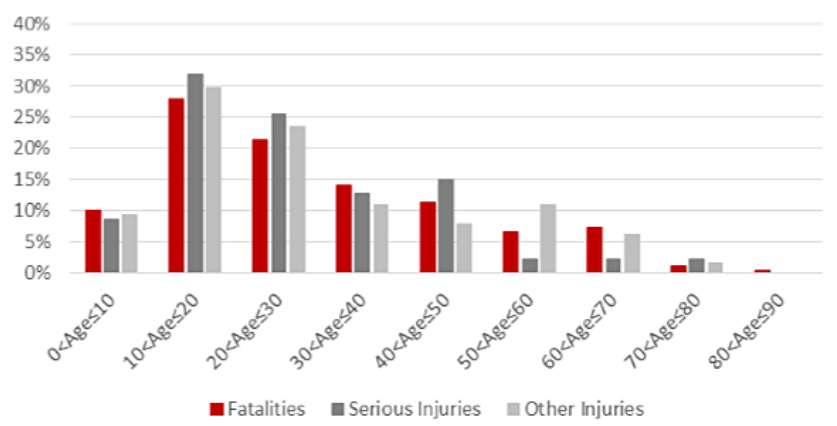

Figure 11. Age distribution of lightning victims by fatalities, serious injuries, and other injuries (January 1930 to June 2014).

than 30. Similarly, $66 \%$ of seriously injured victims and $63 \%$ of injured victims were younger than 30 (Fig. 11).

If an incident occurred in a province or district centre, then it was categorized as urban. If an incident occurred in a town or village, then it was categorized as rural. Most of the incidents $(86 \%)$ occurred in rural areas and only $14 \%$ in urban areas, with 367 records having this information. In the 1950 s, only $25 \%$ of the population were living in urban areas, whereas, by the $2000 \mathrm{~s}, 70 \%$ of the population were living in urban areas (Fig. 12). In each year, the number of incidents was always higher in rural areas during the period (Fig. 13). The percentage of urban incidents was relatively higher for the 1920s-1950s and the 1990s. Relative minima are also present in the total number of incidents for the 1940s and 1990s, suggesting that the higher urban incident rates can be the result of socioeconomic issues that probably affected the reporting from rural areas. For example, poverty due to World War II can be the reason for underreporting from rural areas for the 1940s.

Reports show that 71 of the incidents occurred on farms. Victims of 112 incidents were shepherds, which contributed to the rural occurrences. Hiding under a tree, a common behaviour during heavy rain and hail, resulted in 94 fatalities,
Urban and rural population of Turkey 1927-2010

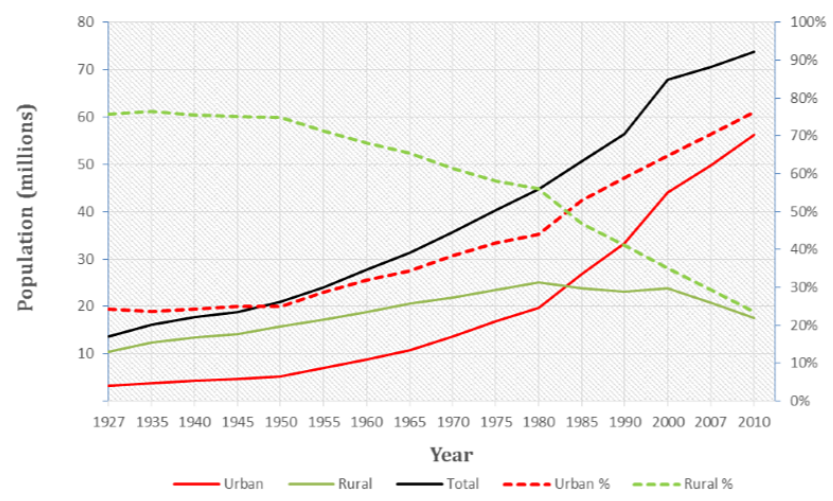

Figure 12. Population distribution of Turkey in rural vs. urban areas between 1927 and 2010 and rural vs. urban percentage in total population for each survey year. The time interval between survey years varies before 1935 and after 1990 (Turkish Statistical Institute).

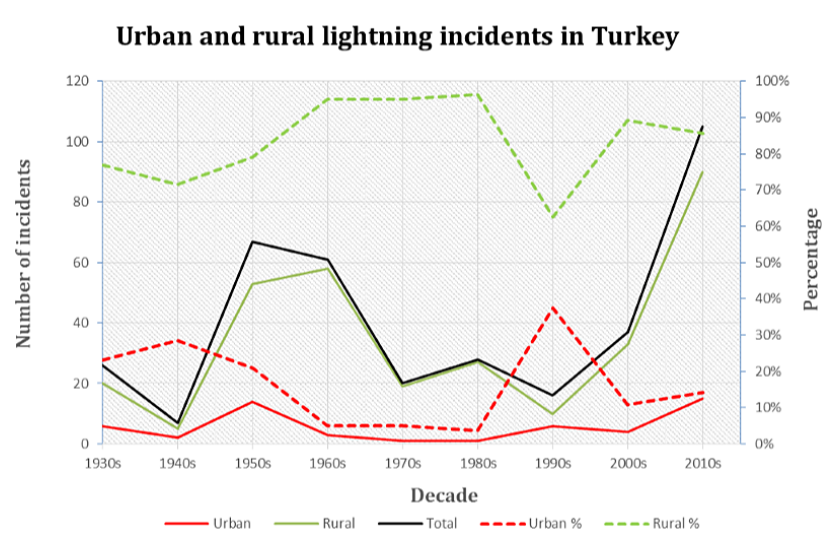

Figure 13. Number and percentage of urban and rural lightning incidents in Turkey by decade between the 1930s and the 2010s ("2010s" include data from January 2010 to the end of June 2014).

25 serious injuries and 85 other injuries due to lightning striking the trees. There were 53 indoor incidents with 53 fatalities, 20 serious injuries and 66 other injuries, usually in farm cottages.

Some of the incidents appeared during transportation. Three people died and one other injured while riding horses. There were 2 incidents with lightning striking cars, causing 5 fatalities and 1 injury. One of the incidents occurred on 5 July 1963 in Kars Province in a rural area in northeastern Turkey (location in Fig. 8) while a family was going to their home from the farm. It resulted in 2 deaths and 1 injury. There was no specific information about the event nor the features of the car that would explain why the Faraday cage of the vehicle did not protect the family. The second incident occurred on 22 February 1993 while a car was on its way to Izmir from Alanya. In this case, the lightning strike to the car resulted in a traffic accident, causing 3 fatalities. 


\section{Summary}

The Turkish State Meteorological Service archive, archives of Cumhuriyet and Milliyet newspapers, internet and the European Severe Weather Database were searched to collect data on lightning-related fatalities and injuries in Turkey. The resulting data set covers January 1930 to June 2014. There were 745 incidents, resulting in 898 deaths, 150 serious injuries and 536 injuries. The total number of fatalities was 31 in 2012, 26 people in 2013 and 25 people in 2014. With a Turkish population of around 73.7 million, the number of fatalities was 0.42 per million in 2012, 0.35 per million in 2013 and 0.34 per million in 2014 (January-June). The total number of human injuries was 36 in each of 2012 and 2013, and 62 in 2014. Considering the population, the rate of injuries was 0.49 per million in each of 2012 and 2013, and 0.84 per million in 2014 (January-June).

Incidents were most frequent in late spring all around Turkey and were rare during winter. The majority of lightning incidents occurred during the afternoon, with fewer occurring at night. The number of incidents was higher over the highly populated western parts, especially in Istanbul and relatively lower in central and eastern Turkey. Geographical, annual and diurnal distributions of the incidents were comparable to thunderstorm and lightning observations, as well as with the report-based severe weather climatologies for Turkey.

The risk of being struck by lightning was highest for the people participating in outdoor activities such as farming and shepherding. The number of male victims was nearly twice the number of female victims. Almost all of the incidents occurred in rural areas. The number of victims under trees is a sign of the need for awareness campaigns.

Acknowledgements. The authors thank journalists, observers working at meteorological stations, volunteers, the Turkish State Meteorological Service and the ESWD for the lightning-related incident reports, the Turkish State Meteorological Service for thunderstorm days data, and Ronald L. Holle and Vaisala for the lightning data. Şeyda Tilev-Tanriover is supported by 2214/A fellowship program of the Scientific and Technological Research Council of Turkey (TÜBİTAK). Partial funding for Schultz was provided by the UK Natural Environment Research Council through grant NE/I024984-1 PRESTO (PREcipitation STructures over Orography).

Edited by: A. Mugnai

Reviewed by: R. L. H. Holle and two anonymous referees

\section{References}

Alyan, O., Ozdemir, O., Tufekcioglu, O., Geyik, B., Aras, D., and Demirkan, D.: Myocardial injury due to lightning strike: A case report, Angiology, 57, 219-223, 2006.
Ashley, W. S. and Gilson, C. W.: A reassessment of US lightning mortality, B. Am. Meteorol. Soc., October 2009, 1501-1518, 2009.

Aslan, S., Yilmaz, S., and Karcioglu, O.: Lightning: an unusual cause of cerebellar infarction, Emergence Medicine Journal, 21, 750-751, 2004.

Aslar, A. K., Soran, A., Yildiz, Y., and Isik, Y.: Epidemiology, morbidity, mortality and treatment of lightning injuries in a Turkish burns units, Int. J. Clin. Pract., 55, 502-504, 2001.

Celiköz, B., Isik, S., Türegün, M., and Selmanpakoğlu, N.: An unusual case of lightning strike: Full-thickness burns of the cranial bones, Burns, 22, 417-419, 1996.

Cumhuriyet Archive, http://www.cumhuriyetarsivi.com, last access: 11 July 2014.

Dlamini Q. M.: Lightning fatalities in Swaziland: 2000-2007, Nat. Hazards, 50, 179-191, 2009.

Elsom, D. M.: Deaths and injuries caused by lightning in the United Kingdom: Analyses of two databases, Atmos. Res., 56, 325-334, 2001.

Elsom, D. M. and Webb, J. D. C.: Deaths and injuries from lightning in the UK, 1988-2012, Weather, 69, 221-226, 2014.

European Severe Weather Database (ESWD), http://www.essl.org/ cgi-bin/eswd/eswd.cgi (last access: 15 July 2014), 2012.

Holle, R. L. and Lopez, R. E.: A comparison of current lightning death rates in the US with other locations and times, Preprints, International Conference on Lightning and Static Electricity, 1618 September, Blackpool, England, Royal Aeronautical Society, paper 103-34 KMS, 7 pp., 2003.

Holle, R. L., Lopez, R. E., and Navarro, B. C.: Deaths, injuries, and damages from lightning in the United States in the $1890 \mathrm{~s}$ in comparison with the 1990s, J. Appl. Meteor., 44, 1563-1573, 2005.

Kahraman, A. and Markowski, P.: Tornado climatology of Turkey, Mon. Weather Rev., 142, 2345-2352, 2014.

Kahraman, A., Tilev-Tanriover, Ş., Kadioğlu, M., Schultz, D. M., and Markowski, P. M.: Severe hail climatology of Turkey, Mon. Weather Rev., submitted, August 2014.

Milliyet Archive, http://gazetearsivi.milliyet.com.tr (last access: 17 July 2014), 2013.

Mills, B., Unrau, D., Parkinson, C., Jones, B., Yessis, J., Spring, K., and Pentelow, L.: Assessment of lightning-related fatality and injury risk in Canada, Nat. Hazards, 47, 157-183, 2008.

Raga, G. B., Parra, M. G., and Kucienska, B.: Deaths by lightning in Mexico (1979-2011): Threat or vulnerability?, Wea. Climate Soc., 6, 434-444, 2014.

Said, R. K., Inan, U. S., and Cummins, K. L.: Longrange lightning geolocation using a VLF radio atmospheric waveform bank, J. Geophys. Res.-Atmos., 115, D23108, doi:10.1029/2010JD013863, 2010.

Said, R. K., Cohen, M. B., and Inan, U. S.: Highly intense lightning over the oceans: Estimated peak currents from global GLD360 observations, J. Geophys. Res.-Atmos., 118, 6905-6915, 2013.

Salerno, J., Msalu, L., Caro, T., and Mulder, M. B.: Risk of injury and death from lightning in Northern Malawi, Nat. Hazards, 62, 853-862, 2012.

Zhang, W., Meng, Q., Ma, M., and Zhang, Y.: Lightning causalities and damages in China from 1997 to 2009, Nat. Hazards, 57, 465476, 2011. 